\title{
Wettbewerb „Biophorie“
}

\section{Mehr Öffentlichkeit für die Biotechnologie}

\author{
CLAUDIA ENGLBRECHT
}

BIO DEUTSCHLAND E. V., BERLIN

DOI: $10.1007 / \mathrm{s} 12268-019-0223-y$

(C) Springer-Verlag 2019

Eine repräsentative Umfrage von 2015 zeigte, dass die Biotechnologie Dreivierteln der Deutschen ein Begriff ist ${ }^{1}$. Im Umkehrschluss bedeutet das aber auch, dass 25 Prozent der Befragten mit dem Begriff nichts anfangen konnten. Weiter gefragt, zeigten sich noch deutlichere Lücken. Dreiviertel unserer Mitbürgerinnen und Mitbürger wissen nicht, dass zahlreiche Lebensmittel während ihrer Produktion in irgendeiner Weise mit Biotechnologie bzw. Gentechnik in Berührung kommen. Nur sage und schreibe 27 Prozent sind sich bewusst, dass Insulin für Diabetiker ein biotechnologisch und gentechnisch hergestelltes Medikament ist, nur ein paar Prozent mehr kennen die Inhaltsstoffe ihres Waschpulvers gut genug, um zu wissen, dass die biologisch aktiven Enzyme darin mithilfe der Gentechnik produziert wurden.

Auch wenn die Umfrage schon etwas zurückliegt, lässt sich daraus doch schließen: Die Biotechnologie braucht dringend mehr Öffentlichkeit. Daher hat BIO Deutschland 2019 das Themenjahr „100 Jahre Biotechnologie" ausgerufen, um auf die zahlreichen Erfolge der Biotechnologie und den Einfluss dieser Schlüsseltechnologie auf unser tägliches Leben aufmerksam zu machen. Warum 100 Jahre, werden Sie sich vielleicht fragen. Die Biotechnologie gibt es doch schon viel länger. Das ist natürlich richtig, aber der Begriff „Biotechnologie“, den laut der Umfrage bei Weitem nicht alle Deutschen kennen, wurde tatsächlich erst 1919 geprägt und das sogar auf Deutsch. Karl Ereky, Direktor der Viehverwertungsgenossenschaft ungarischer Großgrundbesitzer, war der Urheber. Er veröffentlichte vor 100 Jahren sein Buch Biotechnologie der Fleisch-, Fett- und Milcherzeu-

${ }^{1}$ Quelle: Dimap-Umfrage „Gentechnik ist Alltag“ vom September 2015 im Auftrag von BIO Deutschland und dem Forum Grüne Vernunft.

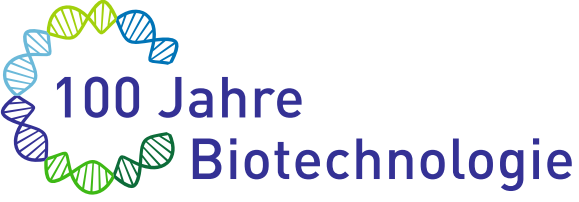

gung im landwirtschaftlichen Großbetriebe für naturwissenschaftlich gebildete Landwirte im Parey-Verlag in Berlin. Ereky erörterte darin die Grundsätze, „nach denen der tierische Organismus als biotechnologische Arbeitsmaschine Lebensmittel erzeugt“. Sein Ziel war die Erhöhung der Fleischproduktion. Insgesamt wies er „alle die Arbeitsvorgänge, bei denen aus Rohstoffen mit Unterstützung lebender Organismen Konsumartikel erzeugt werden, dem Gebiete der Biotechnologie zu“. Mit unserem heutigen Verständnis von Biotechnologie stimmt diese Auffassung insofern überein, als sie auf den Resultaten des Stoffwechsels von Lebewesen basiert.

Die Initiative „100 Jahre Biotechnologie“ gibt Hintergrundinformationen zu wichtigen Meilensteinen der interdisziplinären Wissenschaft. Wir haben im Jahr 1919 mit Karl Ereky begonnen und den Fokus auf herausragende Erfindungen, Entdeckungen und Innovationen der letzten Jahrzehnte gerichtet. Bisher berichteten wir schon von 20 solcher Meilensteine in Pressemitteilungen, von Highlights der Grundlagenforschung sowie Anwendung und Produktion. Auch technologische Revolutionen sind Teil der Geschichte. Werfen Sie unter www.100Jahre-biotech.de einen Blick auf unsere Auswahl. Ein Quiz, um das eigene Biotechnologie-Wissen zu testen, ist dort ebenfalls zu finden.

Dass die Biotechnologie eine Schlüsseltechnologie des 21. Jahrhunderts ist, darin sind sich Wissenschaft und Politik einig. Wie wird nun die Biotechnologie unseren Alltag in diesem Jahrhundert verändern? Das möchte der Biotechnologiebranchenverband BIO Deutschland gerne von den Mitbürgerinnen und Mitbürgern wissen. Im Rahmen des diesjährigen Themenjahres „100 Jahre Biotech- nologie" lädt der Verband ein, an dem Wettbewerb „Biophorie“ - Euphorie für die Biotechnologie - teilzunehmen und Zukunftsvisionen für die Biotechnologie einzureichen. Die Zukunftsvision kann eine kurz- oder mittelfristige sein oder auch einen langfristigen Blick nach vorne werfen. Teilnehmende sollten ihre Idee in maximal 2.000 Zeichen ausführen. Einsendeschluss ist der 31. Oktober 2019. Die drei interessantesten Eingaben werden von einer Jury ausgewählt und die Visionen dann von einem Künstler gezeichnet. Mehr zum Wettbewerb „Biophorie“ finden Sie unter www.100jahre-biotech.de/bio phorie.html.

Wichtige Unterstützer konnten wir für das Themenjahr „100 Jahre Biotechnologie“ schon gewinnen. So freuen wir uns über die Allianzpartner Biotechnologieverbund Berlin-Brandenburg e. V. (bbb), Biotechnologische Studenteninitiative (bts e. V.), Deutsche Akademie der Technikwissenschaften (acatech), Gesellschaft für chemische Technik und Biotechnologie (DECHEMA e. V.), Verband Biologie, Biowissenschaften und Biomedizin (VBIO e. V.), Verein Deutscher Ingenieure (VDI e. V.) und Vereinigung für Allgemeine und Angewandte Mikrobiologie (VAAM e. V.). Weitere Partner sind natürlich herzlich willkommen.

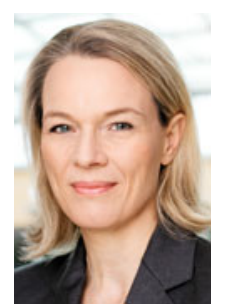

Korrespondenzadresse: Dr. Claudia Englbrecht BIO Deutschland e. V. Schützenstraße 6a D-10117 Berlin Tel.: 030-233216432 englbrecht@biodeutschland.org www.biodeutschland.org 